\title{
Comparison of the Frequency of Billiary Leakage with Clipless Versus Clipped Laparoscopic Cholecystectomy for Management of Cholecystitis.
}

\author{
Bushra Jamil $^{1}$, Aiman Saeed ${ }^{2}$, Humaira Parveen ${ }^{3}$ \\ 1,2,3. House Officer Nishtar Hospital, Multan \\ Corresponding Author: bushrajamil14@yahoo.com
}

Abstract:

Objective: Compare the frequency of billiary leakage with clipless versus clipped laparoscopic cholecystectomy for management of cholecystitis.

Methodology: Randomized control trail study was performed in Department of Surgery Nishtar Medical College Multan from April 2017 to September 2018. Sample size of 130 with 65 patients in two each group was calculated with power of study taken as $80 \%$, significance level $5 \%$ and taking expected percentage of billiary leakage of $30 \%$ with clipped laparoscopic and 10\% with clipless laparoscopic cholecystectomy (6). Non probability consecutive type of sampling technique was used to calculate the sample size. A predesigned Performa was used to collect all the data regarding procedure and outcomes. The data was subjected to statistical analysis using computer software SPSS version 23. Age and duration of cholecystitis were the quantitative variables of which mean and standard deviation was calculated. Frequency and percentage was calculated for qualitative variables like gender and billiary leakage. Chi square test was applied to compare the billiary leakage in both groups with $\mathrm{P}$ value less than 0.05 taken as significant.

Results: , $100 \%(\mathrm{n}=168)$ patients were included, in this study; divided into two equal groups, 50\% ( $\mathrm{n}=84)$ in each, clipless and clipped respectively. The main outcome variable of this study was billiary leakage. The billiary leakage was noted in $23.8 \%(n=20)$ and $44 \%(n=37)$ patients for clipless and clipped groups respectively. Significant difference was found between billiary leakage in groups $\left(\chi^{2}=7.67, p=0.006\right)$. No significant difference was found between billiary leakage and gender $(\mathrm{p}=0.995)$, stratified age $(\mathrm{p}=0.325)$, duration of Cholelithiasis $(\mathrm{p}=0.861)$.

Conclusion: It has been proved in our study that the biliary leakage was statistically significantly higher in the clipped LC for management of Cholecystitis.

Keywords: Billiary Leakage, Clipless Laparoscopy, Clipped Laparoscopy, Cholecystectomy, Cholecystitis

DOI: $10.7176 / \mathrm{JMPB} / 54-05$

Publication date: April $30^{\text {th }} 2019$

\section{Introduction:}

Diseases caused by gallstones are among the commonest clinical anomalies which is present all over the world (1). Cholelithiasis manifests in variety of forms, which range from mild billiary colic to fatal gallstone cholangitis and pancreatitis (2). Multiple diseases caused by gallstones can be listed as, billiary colic, choledocholithiasis, cholecystitis and pancreatitis which usually overlap in their diagnosis (3).

Normally titanium clips are used to secure cystic duct and artery in laparoscopic cholecystectomy. Extra corporeal knotting is considered inferior to intra corporeal ligation in normal situations. Separate and multiple ligations of cystic artery and duct have been reported in many studies, but are considered time consuming and technically demanding. As such, harmonic scalpel and LigaSure are extremely to be afforded by the people of countries with limited resources (4). Harmonic or ultrasonically activated scalpel in both laparoscopic and open surgical procedures for dissection and hemostasis is proved to be safe, efficient and effective instrument.

Most severe adverse affect after cholecystectomy are billiary leakages. Range of clinically relevant billiary leakage after conventional cholecystectomy is 0.1 to $0.5 \%$. Incidence of billiary leakage has increased up to $3 \%$ 
since the development of laparoscopic cholecystectomy during learning curve (5). Treatment of choice for post cholecystectomy billiary leakage is magnetic resonance retrograde cholangiopancreatiography by placing a billiary stent or nasobilliray drain (6).

In a study it was reported that billiary leakage incidence was statistically significant and significantly higher among the patient undergoing clipped laparoscopy as compared to the patients undergoing clipless laparoscopy i.e. $30 \%$ and $10 \%$ respectively with $\mathrm{P}=0.002$ (7). But according to various other studies rate of billiary leakage was comparable in use of clipless harmonic scalpel and clip placement with $1.75 \%$ and $0.66 \%$ respectively. Recommendations were made stating that at the discretion of the surgeon both clipless harmonic scalpel and clip placement are comparable and safe for cystic duct ligation. In order to assess the cost effectiveness of these procedures and to enhance their use in laparoscopic procedures for cholecystectomy, further studies are required especially larger homogenous studies (8).

This study is aimed to compare the frequency of billiary leakage in clipped with clipless laparoscopic cholecystectomy for treatment of cholecystitis. Literature shows that clipless procedure by using harmonic scalpel is much safer and better approach in managing cholecystitis as compared to conventional clipped procedure. But no final decisions have been made because of different controversies regarding these techniques. So this study is conducted to find if clipless is really a better method to precede with, otherwise more appropriate technique must be used in future to prevent patients from postoperative complications. This will help us to improve our practice and in future we will be able to implement the results of this study for management of cholecystitis with minimal post-operative complications.

\section{Materials and Methods:}

Randomized control trail study was performed in Department of Surgery Nishtar Medical College Multan from April 2017 to September 2018. Ethical approval was obtained from Hospital Ethics Committee and informed consent was taken from the patients taking part in the study. Sample size of 130 with 65 patients in two each group was calculated with power of study taken as $80 \%$, significance level $5 \%$ and taking expected percentage of billiary leakage of $30 \%$ with clipped laparoscopic and 10\% with clipless laparoscopic cholecystectomy (7). Non probability consecutive type of sampling technique was used to calculate the sample size. Inclusion criteria was set as, patients with age ranging from 25 to 60 years, either gender, suffering from cholecystitis and undergoing laparoscopic cholecystectomy under general anesthesia. Exclusion was based upon the flowing criteria; patients suffering from diabetes mellitus, hypertension and patients with clotting disorder. Demographic info consisting of names, age, sex and duration of cholecystitis was obtained from the patients. Laparoscopic cholecystectomy under spinal anesthesia was performed in all the patients involved in the study. All procedures were performed by a single surgical team. Patients were randomly divided into two equal groups by using lottery method, A as Clipless and B as Clipped.

Clipless harmonic scalpel was used in patients of group A. Ultrasonic shear through 10mm epigastric port was used for dissection of cystic duct and artery and then gallbladder from liver bed with the help of grasper through midclavicular $5 \mathrm{~mm}$ port in order to reach hemo-billiary stasis, and at the end gallbladder was retrieved from epigastric $10 \mathrm{~mm}$ trocars site.

Conventional instruments with application of clips were used in patients of group B. in all cases a small catheter was placed for drainage which was removed after keeping it for 24 hours. Follow up was arranged in OPD after one week. Magnetic resonance retrograde cholangiopancreatiography was performed to determine the billiary leakage. A predesigned Performa was used to collect all the data regarding procedure and outcomes. The data was subjected to statistical analysis using computer software SPSS version 23. Age and duration of cholecystitis were the quantitative variables of which mean and standard deviation was calculated. Frequency and percentage was calculated for qualitative variables like gender and billiary leakage. Chi square test was applied to compare the billiary leakage in both groups with $\mathrm{P}$ value less than 0.05 taken as significant.

\section{Results:}

Overall, $100 \%(\mathrm{n}=168)$ patients were included, in this study; divided into two equal groups, $50 \%(\mathrm{n}=84)$ in each, clipless and clipped respectively. The mean age and duration of Cholelithiasis of the clipless patients was $42.14 \pm 2.90$ years and $13.61 \pm 2.02$ respectively. There were $64.3 \%(n=54)$ males and $35.7 \%(n=30)$ females. 
While, the mean age and duration of Cholelithiasis of the clipped patients was $45.54 \pm 2.56$ years and $12.08 \pm 1.92$ respectively. There were $65.5 \%(n=55)$ males and $34.5 \%(n=29)$ females. (Table1).

The main outcome variable of this study was biliary leakage. The biliary leakage was noted in $23.8 \%$ $(n=20)$ and $44 \%(n=37)$ patients for clipless and clipped groups respectively. Significant difference was found between biliary leakage in groups $\left(\chi^{2}=7.67, \mathrm{p}=0.006\right)$. (Table. 2$)$.

No significant difference was found between biliary leakage and gender $(p=0.995)$, stratified age $(\mathrm{p}=0.325)$, duration of Cholelithiasis $(\mathrm{p}=0.861)$. (Table. 2$)$.

Table 1

Demographic Variables

\begin{tabular}{|c|c|c|}
\hline Variable & $\begin{array}{c}\text { Clipless } \\
\mathbf{n}=\mathbf{( 8 4 )}\end{array}$ & $\begin{array}{c}\text { Clipped } \\
\mathbf{n}=\mathbf{( 8 4 )}\end{array}$ \\
\hline Age & $42.14 \pm 2.90$ years & $45.54 \pm 2.56$ years \\
\hline Duration of & $13.61 \pm 2.02$ & $12.08 \pm 1.92$ \\
Cholelithiasis & & \\
\hline & $\mathrm{M}=64.3 \%$, & $\mathrm{M}=65.5 \%$, \\
Gender & $\mathrm{F}=35.7 \%$ & $\mathrm{~F}=34.5 \%$ \\
\hline
\end{tabular}

Table 2

Association of biliary leakage with gender, stratified age, duration of Cholelithiasis and groups

\begin{tabular}{|c|c|c|c|c|c|}
\hline \multicolumn{2}{|c|}{ Variable } & \multicolumn{2}{|c|}{ Biliary leakage } & \multirow[t]{2}{*}{ Total } & \multirow[t]{2}{*}{ P-value } \\
\hline & & Yes & No & & \\
\hline \multirow[t]{2}{*}{ Gender } & Male & 37 & 72 & 109 & \multirow[t]{3}{*}{0.995} \\
\hline & Female & 20 & 39 & 50 & \\
\hline \multicolumn{2}{|c|}{ Total } & 57 & 111 & 168 & \\
\hline \multirow[t]{2}{*}{ Stratified Age } & $\leq 45$ years & 11 & 29 & 40 & \multirow[t]{3}{*}{0.325} \\
\hline & $>45$ years & 46 & 82 & 128 & \\
\hline \multicolumn{2}{|c|}{ Total } & 57 & 111 & 168 & \\
\hline \multirow{2}{*}{$\begin{array}{l}\text { Duration of } \\
\text { Cholelithiasis }\end{array}$} & $\leq 45$ Minutes & 27 & 51 & 78 & \multirow[t]{3}{*}{0.861} \\
\hline & $>45$ Minutes & 30 & 60 & 90 & \\
\hline \multicolumn{2}{|c|}{ Total } & 57 & 111 & 168 & \\
\hline Groups & Clipless & 20 & 64 & 84 & \multirow{3}{*}{0.006} \\
\hline & Clipped & 37 & 47 & 84 & \\
\hline \multicolumn{2}{|c|}{ Total } & 57 & 111 & 168 & \\
\hline
\end{tabular}




\section{Discussion:}

Reports have shown that laparoscopic cholecystectomy is a safe, economical and simple procedure (9). Securing of cystic duct and artery during laparoscopic cholecystectomy can be achieved by multiple techniques, like intra or extra corporeal ligation, clips, harmonic scalpel and LigaSure (10). Use of harmonic scalpel and LigaSure during laparoscopic cholecystectomy is a recent advent $(11,12)$. Our results show that biliary leakage was present in 57 patients of which 20 patients belonged to clipless group while 37 belonged to clipped group. In our study clipless group showed statistically less biliary leakage as compared to clipped group $(\mathrm{P}=0.006)$, but it is not significant. PK Saha et al (4) performed a study in Bangladesh and found that clipless laparoscopic cholecystectomy was safe and effective technique. There was no bile leak related to ligature neither was any other postoperative complication. In a study it was reported that biliary leakage incidence was statistically significant and significantly higher among the patient undergoing clipped laparoscopy as compared to the patients undergoing clipless laparoscopy i.e. $30 \%$ and $10 \%$ respectively with $\mathrm{P}=0.002$ (7).

A study conducted in the city of Rawalpindi, Pakistan which concluded that despite the difference of the procedure performed i.e. clipless and clipped laparoscopic cholecystectomy, there was no difference in the frequency of bile leak among the two groups (bile leak was present in two patients of each group) with $\mathrm{P}=0.972$ (13). Tharwat Kandil et al (11) performed a study which concluded that harmonic scalpel provided a more complete hemo-biliary stasis and can be recommended as a safe alternative to traditional clip of cystic duct and artery. It provides a shorter operative duration, less incidence of gallbladder perforation, less postoperative pain, and less rate of conversion to open cholecystectomy. In one study, bile leaks were reported in 9 of 331 patients $(2.7 \%)$ when a harmonic scalpel was used alone (12). A study of 100 LCs performed using a harmonic scalpel recommended that additional cystic duct ligatures be used for a cystic diameter exceeding $5 \mathrm{~mm}(12,14)$. One more study has also showed that bile leak was encountered in $1.7 \%$ with clipless method and $3.3 \%$ with clipped method $(\mathrm{p}=0.45)(9)$.

In our study the mean value of duration of Cholelithiasis in clipless group was $13.61 \pm 2.02$ minutes and its mean value in clipped group was $12.08 \pm 1.92$ minutes. The incidence of gallbladder perforation was statistically comparable in the $\mathrm{C} \& \mathrm{C}$ group, compared to the HS group. Besides being equally safe, advantages to clipless cholecystectomy by means of harmonic shears versus conventional LC is a shorter operative time, less incidence of gallbladder perforation, less postoperative pain and less rate of conversion to open cholecystectomy (11). A study by Roberta Gelmini et al (15) presented that the mean operative time was significantly shorter in patients treated with the Harmonic scalpel. The Harmonic scalpel is not only a safe and effective instrument but also a reliable substitute for clips because it provides complete hemobiliary stasis which is in accordance to our study results. In recent studies harmonic scalpel was compared with conventional clipped laparoscopy and results show that harmonic scalpel use was much more effective in terms of providing hemobiliary status and duration of surgery $(16,17,18$ and 19$)$.

\section{Conclusion:}

It has been proved in our study that the billiary leakage was statistically comparable in the clipped and clipless LC for management of Cholecystitis

\section{Conflict of Interest:}

There was no conflict of interest reported regarding this study.

\section{Funding Source:}

There was no external funding source.

\section{References:}

1- Stinton LM, Shaffer EA. Epidemiology of gallbladder disease: cholelithiasis and cancer. Gut and liver. 2012 Apr;6(2):172.

2- Luu MB, Deziel DJ. Unusual complications of gallstones. Surgical Clinics. 2014 Apr 1;94(2):377-94.

3- Demehri FR, Alam HB. Evidence-based management of common gallstone-related emergencies. Journal of intensive care medicine. 2016 Jan;31(1):3-13. 
4- Saha PK, Roy RR, Rahman M, Khan EH, Reza SM, Rabbani MG, Alom KS. Clipless Laparoscopic Cholecystectomy: An initial experience of 50 cases in Bangladesh. Journal of Science Foundation. 2016 May 22;13(1):11-4.

5- Weber A, Feussner H, Winkelmann F, Siewert JR, Schmid RM, Prinz C. Long-term outcome of endoscopic therapy in patients with bile duct injury after cholecystectomy. J Gastroenterol Hepatol 2009;24(5):762-9.

6- Chinnery GE, Krige JE, Bornman PC, Bernon MM, Al-Harethi S, Hofmeyr S, Banderker MA, Burmeister S, Thomson SR. Endoscopic management of bile leaks after laparoscopic cholecystectomy. South African Journal of Surgery. 2013 Jan;51(4):116-21.

7- Bessa SS, Al-Fayoumi TA, Katri KM, Awad AT. Clipless laparoscopic cholecystectomy by ultrasonic dissection. J Laparoendosc Adv Surg Tech 2008;18(4):593-8.

8- Wills E, Crawford G. Clipless versus conventional laparoscopic cholecystectomy. J Laparoendosc Adv Surg Tech 2013;23(3):237-9

9- Saha SK. Ligating the cystic duct in laparoscopic cholecystectomy. The American journal of surgery 2000;179(6):494-6.

10- Meng MV, Stoller ML. Laparoscopic intracorporeal square-to-slip knot. Urology 2002;59(6):932-3.

11- Kandil T, E1 Nakeeb A, El Hefnawy E. Comparative study between clipless laparoscopic cholecystectomy by harmonic scalpel versus conventional method: a prospective randomized study. Journal of Gastrointestinal Surgery 2010;14(2):323-8.

12- Hüscher C, Lirici M, Di Paola M, Crafa F, Napolitano C, Mereu A, et al. Laparoscopic cholecystectomy by ultrasonic dissection without cystic duct and artery ligature. Surgical Endoscopy And Other Interventional Techniques 2003;17(3):442-51.

13- Hassan H, Khan MM, Iqbal M. Clipless Laparoscopic Cholecystectomy by Ultrasonic. Ann Pak Inst Med Sci 2012;8(4):229-31.

14- Bessa SS, Al-Fayoumi TA, Katri KM, Awad AT. Clipless laparoscopic cholecystectomy by ultrasonic dissection. Journal of Laparoendoscopic \& Advanced Surgical Techniques 2008;18(4):593-8.

15- Gelmini R, Franzoni C, Zona S, Andreotti A, Saviano M. Laparoscopic cholecystectomy with Harmonic scalpel. Jsls 2010;14(1):14.

16- Singh K, Gupta S, Kumar V, Garg V. Comparison of laparoscopic cholecystectomy performed using harmonic scalpel as the sole instrument or by using standard clip and electrocautery Technique. International Journal of Contemporary Medical Research. 2016;3:3043-6.

17- Husain A, Pathak S, Firdaus H. Assessment of operative predictors for difficulty in laproscopic cholecystectomy. International Journal of Contemporary Medical Research. 2016;3:1232-4.

18- Minutolo V, Licciardello A, Arena M, Nicosia A, Di Stefano B, Calì G, Arena G. Laparoscopic cholecystectomy in the treatment of acute cholecystitis: comparison of outcomes and costs between early and delayed cholecystectomy. Eur Rev Med Pharmacol Sci. 2014 Dec;18(2):40-6.

19- Elshoura AA, Saber SA, Elshora OA. Efficacy of harmonic scalpel in total clipless laproscopic cholecystectomy. INTERNATIONAL JOURNAL OF MEDICAL RESEARCH \& HEALTH SCIENCES. 2016 Jan 1;5(2):29-35. 